Jurnal Ilmiah Matematika dan Pendidikan Matematika (JMP)

Vol. 11 No. 2, Desember 2019, hal. 29-36

ISSN (Cetak) : 2085-1456; ISSN (Online) : 2550-0422

\title{
DEPTH FIRST SEARCH (DFS) UNTUK MENENTUKAN \\ DIAMETER GRAF HIRARKI
}

\author{
Nugroho Arif Sudibyo \\ Universitas Duta Bangsa \\ nugroho_arif@udb.ac.id
}

\section{Ardymulya Iswardani \\ Universitas Duta Bangsa \\ ardymulya@udb.ac.id}

\begin{abstract}
Let $G=(V, E)$ be a graph. The distance $d(u, v)$ between two vertices $u$ and $v$ is the length of the shortest path between them. The diameter of the graph is the length of the longest path of the shortest paths between any two graph vertices $(u, v)$ of a graph, $\operatorname{Diam}(G)=\max \{E(v) / v \in V\}$. In this paper we propose algorithms for finding diameter of a hierarchy graph using DFS. Diameter of the hierarchy graph using DFS algoritm is four.
\end{abstract}

Keywords: diameter, hierarchy, depth first search

\begin{abstract}
ABSTRAK. Misalkan $G=(V, E)$ adalah suatu graf. Jarak $d(u, v)$ di antara dua titik u dan titik v adalah panjang dari lintasan terpendek di antara dua titik tersebut. Diameter dari suatu graf adalah lintasan terjauh terpendek di antara sembarang dua titik $(\mathrm{u}, \mathrm{v})$ dari suatu graf, $\operatorname{Diam}(G)=\max \{E(v) \mid v \in V\}$. Dalam makalah ini akan diselidiki tentang algoritma untuk menentukan diameter suatu graf hirarki menggunakan DFS. Diameter Graf Hirarki yang dicari menggunakan algoritma DFS tersebut adalah empat.
\end{abstract}

Kata Kunci: diameter, hirarki, depth first search

\section{PENDAHULUAN}

Model topologi jaringan merupakan istilah untuk menunjukan konfigurasi kabel, komputer dan periperal. Pemodelan ini berfungsi sebagai pengelolaan jaringan komputer yang bertujuan untuk memudahkan dalam mengenali kesalahan, kinerja jaringan komputer, keamanan jaringan komputer hingga akuntabilitas jaringan komputer. (CISCO, 2018; Winkelman, 2013). Topologi tersebut dianggap sebagai peta untuk mengenali titik apa saja yang berada dalam jaringan komputer. Titik merupakan istilah untuk menyebut komputer server, komputer client maupun perangkat jaringan seperti Switch HUB, HUB, access point, router, dan lain sebagainya. 
Topologi jaringan komputer yang ada saat ini yaitu bus, bintang, pohon, cincin, mesh hingga hybrid (Studytonight, 2019). Setiap topologi memiliki karakteristik tersendiri. Kelebihan dan kekurangan yang dimiliki oleh tiap topologi ini yang mendasari pengembangan model topologi dimasa mendatang. Model topologi jaringan terdiri dari titik yang mewakili perangkat komputer dan jaringan dan lintasan komunikasi antar titik. Setiap titik dapat berupa perangkat komputer jaringan individu maupun kelompok.

Peran topologi sebagai penunjuk posisi titiks dalam jaringan komputer tersebut dilengkapi dengan mekanisme sistem pengelolaan jaringan dengan membagi jaringan berdasarkan hirarki/tier/tingkat (Kurose \& Ross, 2008). Pembagian hirarki ini bertujuan agar pemetaan kinerja jaringan komputer dapat dilakukan secara adil/fair. Pembagian ini umumnya dibagi menjadi tiga hirarki yaitu tierl, tier2 dan tier3. tierl berfungsi sebagai pangkalan data atau pusat data. tier2 berfungsi sebagai middleware yang bertanggung jawab terhadap kualitas data yang diterima dari tier3 dan kualitas data yang dikirimkan ke tierl. tier3 berfungsi sebagai alat untuk mengumpulkan data dalam jaringan komputer lokal. Sistem manajemen jaringan dengan model hirarki ditunjukan Gambar 1.

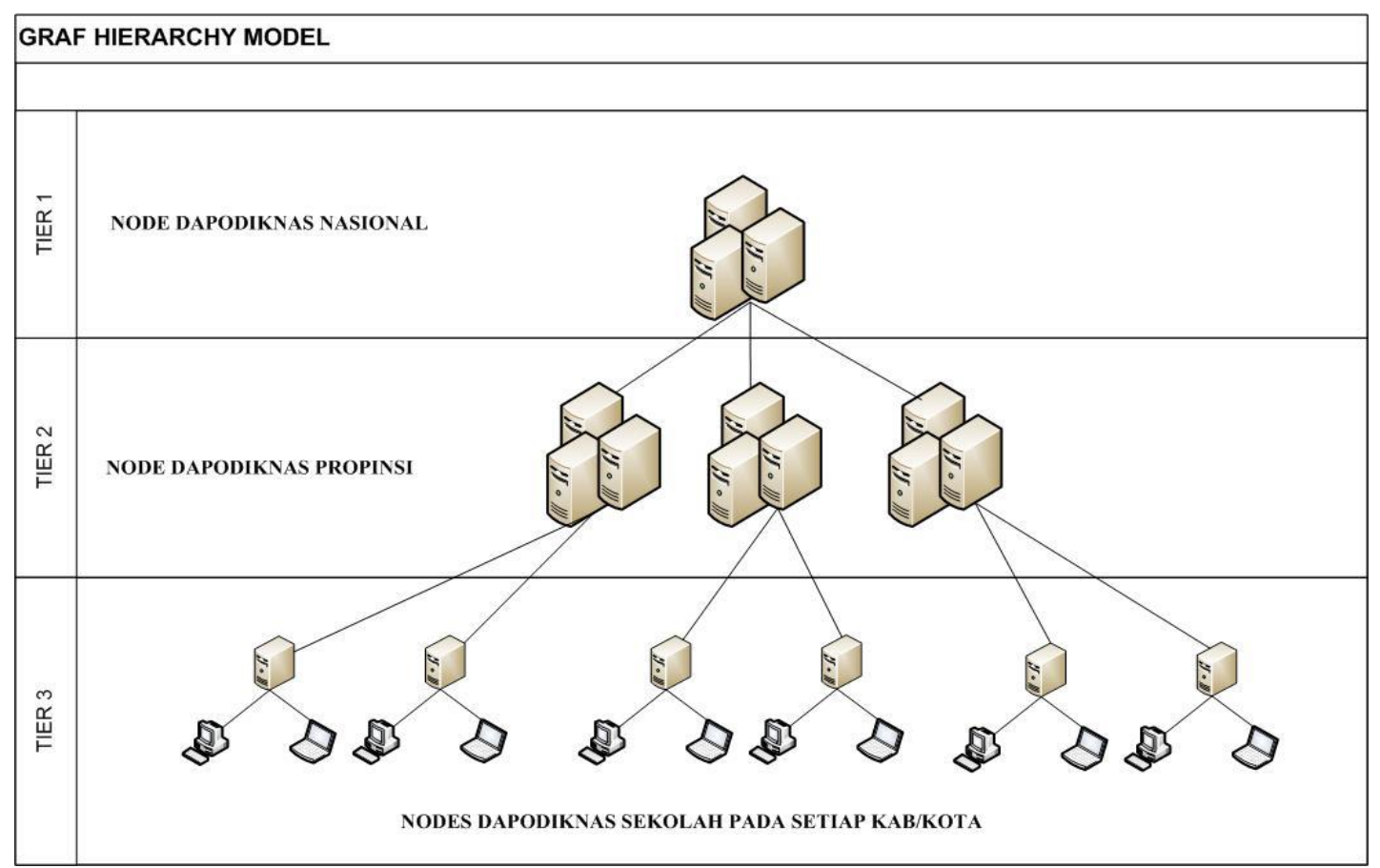

Gambar 1.1 Model hirarki 
Gambar 1.1 menunjukan pembagian beban pemrosesan pada setiap tier. Pembagian bermodel hirarki ini untuk menunjukan peran server dan client untuk setiap tier. Misal client pada tier3 dilayani oleh komputer server pada tier2, kemudian data yang telah diperoleh dari tier3 diproses oleh komputer client pada tier2 untuk dikirimkan pada komputer server di tierl.

Pembagian jaringan komputer menjadi tiga tier ini bertujuan untuk mencapai QoS (Quality of Service) pada derajat tertentu. Kualitas layanan yang diberikan untuk setiap tier akan bervariasi, hal ini dipengaruhi oleh berbagai macam faktor seperti spesifikasi perangkat yang digunakan, kualitas bahan perangkat yang digunakan, besar kecilnya volume data, tinggi rendahnya lalu lintas data hingga beban kerja pemrosesan setiap tier dan faktor sumberdaya manusia. Derajat QoS tersebut bertujuan untuk menjamin kualitas layanan yang diberikan pada pengguna akhir untuk setiap tier (Denko, Yang, et al., 2009). Kualitas layanan ini digunakan untuk mengetahui kinerja jaringan komputer berdasarkan feedback pengguna jaringan komputer sistem dapodik. Istilah titiks dan jalur dalam topologi jaringan komputer serupa dengan teori graf. Model topologi hirarki bertujuan untuk membagi beban kerja berdasarkan struktur hirarki yang disebut tier.

Teori graf sebagai cabang disiplin matematika berkembang cepat. Penerapan teori graf antar disiplin ilmu sebagai alasan utama pemilihan metode. Teori graf telah berkembang cepat sebagai cabang matematika, hal tersebut dibuktikan dengan banyaknya hasil penelitian yang dipublikasikan, sebagai contoh sudah lebih dari dua ribu makalah sudah diterbitkan (Gallian, 2018). Hal tersebut terjadi karena aplikasinya yang luas dalam berbagai masalah.

Teori graf secara formal dapat didefinisikan sebagai himpunan tak kosong berhingga $V$ yang disertai relasi yang irrefleksif dan simetris. Teori graf tidak hanya suatu kajian teori akan tetapi teori graf telah diaplikasikan pada berbagai bidang. Sebagai contoh, jaringan interkoneksi (Kamalesh dan Srivatsa, 2008) dan eksentrisitas dari titik, radius, dan diameter pada jaringan Caccetta dan Vijayan (1987), Caccetta (1989) dan Caccetta (1993). Pada makalah ini diasumsikan graf tree merupakan graf yang tidak berarah. 
Pada makalah ini akan dibahas model hirarki yang akan dimodelkan dalam teori graf supaya dapat ditinjau topologinya. Graf hirarki $H_{m, n}$ adalah suatu tree dengan himpunan titik

$$
V\left(H_{n, m}\right)=\left\{u, v_{1}, v_{2}, \ldots, v_{n}, v_{1,1}, v_{1,2}, \ldots, v_{1, m_{1}}, \cdots, v_{n, 1}, v_{n, 2}, \ldots, v_{n, m_{n}}\right\}
$$

Graf hirarki $H_{m, n}$ disajikan pada Gambar 1.2.

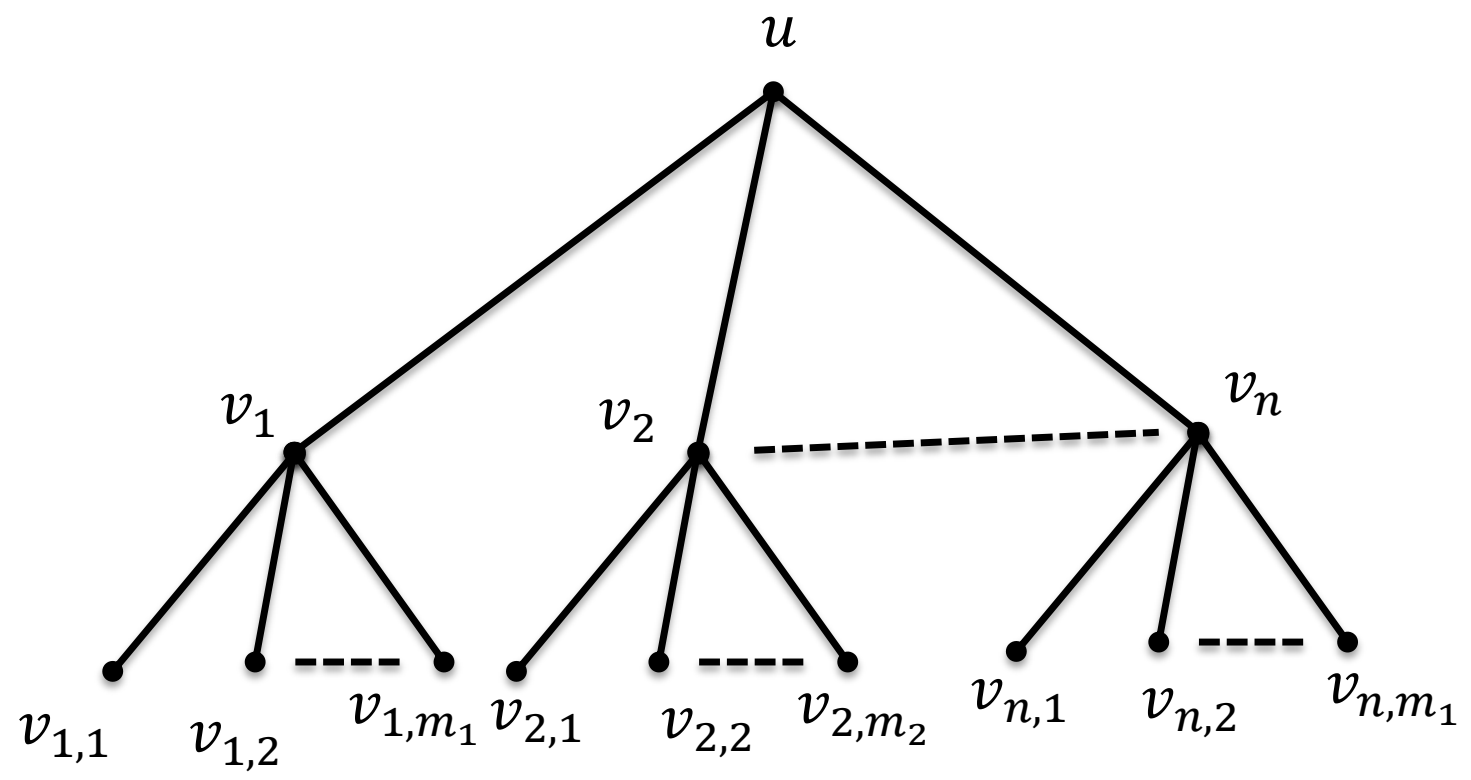

Gambar 1.2 Graf Hirarki

Teori graf menjelaskan, untuk mencari suatu tree dapat digunakan algoritma Depth-First Search (DFS) dan Breadth-First Search (BFS) (Pribadi, 2015). Algoritma tersebut adalah algoritma pencarian buta yang digunakan dalam kecerdasan buatan (Kandaga dan Hapendi, 2008). Algoritma DFS diperkenalkan pertama kali oleh Tarjan dan Hopcroft. Salah satu masalah yang paling mendasar pada teori graf adalah masalah pencarian. Salah satu algoritma yang paling sederhana untuk menyelesaikan masalah tersebut adalah algoritma DFS. Dalam mencari algoritma DFS digunakan matrik adjacency. Matrik adjacency adalah suatu matrik yang menghubungkan titik dengan titik dengan suatu nilai tertentu pada suatu graf. 


\section{METODOLOGI PENELITIAN}

Penelitian ini merupakan kajian ilmu murni yang bersifat studi literatur. Oleh karenanya pendekatan yang digunakan bersifat eksploratif dan adaptif yaitu memanfaatkan pengetahuan yang penulis miliki dari penelitian-penelitian sebelumnya. Selain itu digunakan juga hasil-hasil penelitian yang telah ada di literatur. Penyelesaian permasalahan tersebut dilakukan tahapan-tahapan sebagai berikut.

1. Studi literatur terkait penelitian.

2. Masukkan semua titik pada graf hirarki kemudian buatlah matriks adjacency.

3. Tentukan jarak terpendek dari setiap titik pada graf hirarki.

4. Tentukan eksentrisitas dari setiap titik pada graf hirarki.

5. Tentukan diameter setiap titik pada graf hirarki.

\section{ALGORITMA UNTUK MENCARI DIAMETER}

Notasi dan terminologi mengacu pada Sudibyo dan Kusmayadi (2017). Misalnya diberikan graf $G$ yang terhubung, pasti terdapat suatu lintasan yang menghubungkan titik $v$ dan titik lain dalam $G$. Salah satu algoritma yang dapat mencari diameter adalah algoritma DFS. Selanjutnya, dalam makalah ini akan dibahas algoritma untuk mencari diameter dengan menggunakan DFS mengacu pada hasil penelitian Baidari, et. al (2012).

Input: $n$ - number of titiks

Cost[50][50] - adjacency matrix

Output: Eccentricity, Diameter and Radius

1. Input the number of nodes and adjacency matrix

2. For $i \leftarrow 0$ to $n-1$

$$
\begin{aligned}
& \text { for } j \leftarrow 0 \text { to } n-1 \\
& \qquad D[i][j]=\operatorname{cost}[i][j]
\end{aligned}
$$

End $j$

End $i$

3. To find the shortest distance 


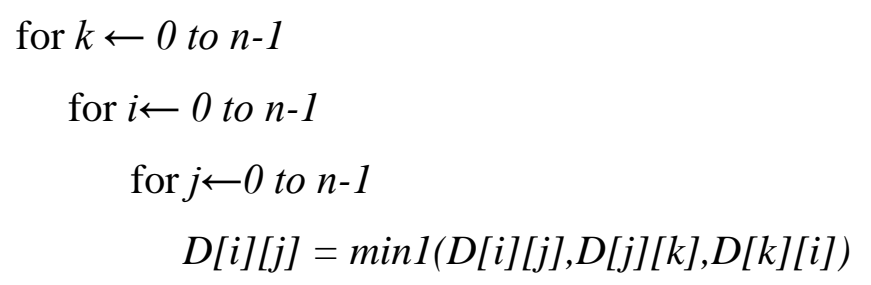

\section{End $j$}

\section{End $i$}

End $k$

4. Initialize min and $\max =e[0]$ for $i \leftarrow 0$ to $n-1$

if $e[i]>\max$

$\max =e[i]$

else if $e[i]<\min$

$\min =e[i]$

End $i$

Diameter $=\max$.

\section{DIAMETER DARI GRAF HIRARKI}

Menentukan diameter pada teori graf tampaknya cukup memakan waktu, tetapi akan dibatasi pada kelas graf tree. Eksentrisitas dari titik $x$ adalah $E(x)=\max _{y \in V} d(x, y)$, di mana $d(x, y)$ menunjukkan jarak antara $x$ dan $y$, diameter $G$ sama dengan eksentrisitas maksimum dari setiap titik di $V$. Misalkan $G$ adalah graf dan $v$ adalah simpul $G$. Secara umum, diameter $G$ adalah eksentrisitas maksimum di antara simpul $e$, sehingga diperoleh bahwa $\operatorname{Diam}(G)=\max \{E(v) \mid v \in V\}$.

Lema 1. Diberikan Graf Hirarki $H_{n, m}$ dengan $n, m \geq 2$, maka diameter dari Graf Hirarki adalah empat.

Bukti. Dengan menggunakan Algoritma DFS dapat diketahui jarak terjauh dari titik $u$ ke titik $v_{i, m_{i}}$ adalah dua dengan $i \in\{1,2, \cdots, n\}$. Jadi eksentrisitas titik $u$ adalah dua. Jarak terjauh dari titik $v_{i}$ ke titik $v_{j, m_{j}}$, dengan $i \neq j$, adalah tiga dengan $i, j \in\{1,2, \cdots, n\}$. Jadi eksentrisitas titik $v_{i}$ adalah tiga. Selanjutnya, jarak 
terjauh dari titik $v_{i, m_{i}}$ ke titik $v_{j, m_{j}}$, dengan $i \neq j$, adalah empat dengan $i, j \in$ $\{1,2, \cdots, n\}$. Jadi eksentrisitas titik $v_{i, m_{i}}$ adalah empat. Dari eksentrisitas setiap titik dari graf hirarki tersebut, jelas bahwa eksentrisitas terbesar yang diperoleh adalah empat sebagai nilai diameter dari graf hirarki.

Penelitian ini menemukan bahwa model hirarki yang telah dimodelkan dalam graf hirarki mempunyai diameter sebesar empat, sehingga apabila topologi jaringan berbentuk seperti model hirarki akan mengakibatkan jarak terjauh terpendek diantara sembarang dua titik yang terkoneksi adalah empat. Namun demikian, diperlukan penelitian lanjutan terkait topologi jaringan yang lain pada model hirarki tersebut.

\section{KESIMPULAN}

Penelitian yang telah dilakukan menemukan dan menyimpulkan beberapa hal sebagai berikut :

1. Langkah penentuan diameter yaitu dengan menyusu matrik adjaceny yang bekerja dengan menemukan jarak terpendek dari setiap titik dalam menentukan diameter pada setiap titik.

2. Diameter dari graf hirarki yang dicari menggunakan algoritma DFS adalah empat.

\section{DAFTAR PUSTAKA}

Baidari, I., Roogi, R. and Shinde, S., Algorithmic Approach to Eccentricities, Diameters and Radii of Graphs using DFS, International Journal of Computer Applications, 54(18) (2012), 1-4.

Caccetta, L. and Vijayan, K., Applications of graph theory, ARS Combinatoria, 23(B) (1987), 21-77.

Caccetta, L., Graph theory in network design and analysis.in Kulli, V.R. (ed.). Recent Studies in Graph Theory, Vishwa International Publications, India, (1989), 26-63. 
Caccetta, L., Graph theory modeling and applications, in M. McAleer and A. Jakeman, eds., International Congress on Modeling and Simulation', Uniprint, University of Western Australia, Perth, (1993), 1265-1270

Chartarand, G. \& Oellermann, O. R., Applied and Algorithmic Graph Theory, Mc Graw-Hill Inc, 1993

CISCO, Network Management System: Best Practices White Paper. https://www.cisco.com/c/en/us/support/docs/availability/highavailability/15114-NMS-bestpractice.html\#networkmanage, 2018

Denko, M. K., Yang, L. T., \& Zhang, Y. (Eds.), Autonomic Computing and Networking, Springer, 2009.

Gallian, J. A., Dynamic Survey of Graph Labeling, The Electronic Journal of Combinatorics, 21 (2018), 1-502.

Kandaga, T. \& Hapendi, A., Evaluasi dan Usaha Optimalisasi Algoritma Depth First Search dan Breadth First Search dengan Penerapan pada Aplikasi Rat Race dan Web Peta, Jurnal Informatika, 4(1) (2018), 39 - 47.

Kurose, J. F, \& Ross, K. W., Computer networking : a top-down approach, 2008.

Pribadi, O., Maze Generator Dengan Menggunakan Algoritma Depth-FirstSearch, Jurnal TIMES, 4(1) (2015), 1-5.

Studytonight, Types of Network Topology, https://www.studytonight.com/computer-networks/network-topologytypes , 2019.

Sudibyo, N. A. \& Kusmayadi, T. A., Pendekatan Algoritma Untuk Mencari Eksentrisitas Suatu Tree dengan Depth First Search, Jurnal Duta.com, 12(2) (2017), 9-14.

Winkelman, R., Topology, https://fcit.usf.edu/network/chap5/chap5.htm, 2013 